\title{
Exploring Strategy Implementation Consistency Over Time: The Moderating Effects of Industry Velocity and Firm Performance
}

\author{
MATTHIAS BRAUER ${ }^{1, *}$ and SASCHA L. SCHMIDT ${ }^{2}$ \\ ${ }^{1}$ Institute of Management, University of St.Gallen, Dufourstrasse 40a, CH-9000, St.Gallen, \\ Switzerland (*Author for correspondence, E-mail: matthias.brauer@unisg.ch); ${ }^{2}$ European \\ Business School, University of St.Gallen, Dufourstrasse 40a, CH-9000, St.Gallen, Switzerland
}

\begin{abstract}
In this paper we empirically investigate the temporal development of a firm's strategy implementation consistency (SIC), i.e. the alignment between firms' resource allocation decisions (RAD) and their articulated corporate concept (Noda and Bower, 1996; Burgelman and Grove, 1996; Love et al., 2002; Mintzberg, 1978). Doing so, we test whether (1) SIC is more likely to increase or decline over time, (2) whether firms competing in (low) high-velocity environments in fact show different temporal patterns in SIC, and (3) whether overperforming firms succeed in conserving their level of SIC. For our analysis we draw on 6238 RAD of 20 publicly listed firms with European origin over a period of 4-6 years. Applying maximum likelihood ordered logit estimation, our results indicate that the likelihood of an alignment of RAD and a firm's corporate concept decreases over time. In line with scholars' perception of high-velocity environments, we find that the firms in our sample competing under such conditions show no clear trend in SIC. These firms tend to "zig-zag" over time - swaying off and pulling back to their strategic course independent of the timing of the announcement of a corporate concept. We also find that overperforming firms are unsuccessful in preserving their SIC at the same level over time. Based on the empirical findings the paper discusses implications for theory and derives suggestions for corporate level managers on how to balance SIC and strategic flexibility.
\end{abstract}

Key words: corporate concept, resource allocation decisions, strategy formation, strategy implementation consistency

\section{Introduction}

Strategy formation has always been an integral component of strategic management research. Particularly noteworthy in this area are the theoretical and empirical works from Mintzberg (1977, 1978, 1990a, b, 1994a, b); Mintzberg and Waters 1982, 1984, 1985); Mintzberg and McHugh (1985). Mintzberg started to deconstruct the view of strategy formation as a topdown, analytical process and introduced the conception that strategy forms 
as "a pattern in a stream of decisions" over time (Mintzberg, 1978, p. 934). Based on this view, initially intended strategies may remain unrealized; whilst new unforeseen elements may emerge in the strategy formation process, in order that "strategies can form without being formulated" (Mintzberg, 1994, p. 26).

Today, the interest in strategy formation has revived. In the midst of recent corporate governance scandals and breakdowns of formerly reputable firms, inconsistencies between intended and realized strategies have become more closely scrutinized (Schmidt and Brauer, 2005, 2006.) The parlance, however, has slightly changed. Discussions of whether manager's "walk their talk" (McGregor, 1967; Weick, 1995), show "word-deed alignment" (Jörg et al., 2004; Simons, 1999, 2002a, b; Simons and Roberson, 2003) or "adhere to their plans" (Covin and Slevin, 1998; Covin et al., 1997) have emerged.

Strategic decisions that are inconsistent with a firm's explicitly articulated corporate concept, however, may not necessarily be due to shortcomings in corporate governance and/or deceptive and fraudulent managerial behavior. Instead, inconsistencies may be inherent to the strategy implementation process itself and contingent upon external and internal context factors (e.g., industry velocity). Therefore, we investigate strategy implementation consistency, i.e. the alignment of firms' resource allocation decisions (Bower, 1970; Burgelman and Grove, 1996; Love et al., 2002; Mintzberg, 1978; Noda and Bower, 1996) with their articulated corporate concept over time (Burgelman, 1983a-c, 1991, 1994, 1996). ${ }^{1}$

Given that our current knowledge on the development of strategy implementation consistency over time is almost exclusively based on conceptual works or qualitative empirical studies, we conducted a quantitative research study. Doing so, we derive and test three hypotheses on the development of strategy implementation consistency over time.

First, we question the general presumption that the "alignment between a firm's strategic intent and strategic actions is not likely to last" and that "inevitably, strategic actions will diverge from strategic intent" (Burgelman and Grove, 1996, p. 8; Richter and Schmidt, 2005).

Second, we explore the influence of the external environment (high versus low velocity) on the development of a firm's strategy implementation consistency over time. Strategy implementation consistency has generally been assumed to be particularly difficult to achieve for firms facing continuous, rapid change (Bogner and Barr, 2000; Eisenhardt, 1989; Eisenhardt and Brown, 1999; Shimizu and Hitt, 2005). Moreover, firms competing in highvelocity environments have been argued to resort to "strategic flexibility" in the sense that they place less emphasis on the realization of their intended strategy but rather strive for flexibly remapping resources according to emerging market opportunities (Hamel et al., 1999; Hitt et al., 1999). 
Third, in line with the general conception of strategy implementation consistency as a hallmark of overperforming, i.e. financially superior firms, (Drazin and Van de Ven, 1985; Khandwalla, 1977; Love et al., 2002), we analyze the potential impact of a firm's financial situation on strategy implementation consistency over time. Doing so we analyze 6238 resource allocation decisions by 20 publicly listed firms with European origin over a period of 4-6 years.

Overall, our empirical results suggest that at least for underperforming firms strategy implementation consistency is likely to decline over time. Further, we find supporting evidence that firms competing in high-velocity environments in fact display an oscillating strategy implementation behavior, which does not seem to be a function of time. Strategy implementation rather seems opportunity driven. Contrary to conventional expectations, overperforming firms seem unable - or maybe unwilling - to conserve high levels of strategy implementation consistency.

Our quantitative study complements and extends prior qualitative strategy process studies (Bower, 1970; Burgelman, 1983a, b; Mintzberg and McHugh, 1985) by unravelling whether firms persist with or diverge from intended corporate strategies - either in a planned or unplanned way. The empirical findings extend the theoretical debate on how strategy implementation develops over time, and how it is impacted by contextual influences such as the velocity of the environmental context or the financial situation of a company. Although our paper is geared towards an academic audience, it still addresses a major practical issue and derives tentative suggestions for corporate level managers on how to balance strategy implementation consistency and strategic flexibility.

\section{Literature Review and Hypotheses}

A firm's strategy implementation consistency is obviously influenced by a number of firm specific factors such as the level of financial or strategic control (Bower, 1970), a firms' governance system (Schmidt and Brauer, 2005, 2006) or the firm's structural context determination (Burgelman, 1983a-c, 1991, 1994, 1996). A firm's articulated corporate concept, however, is widely acknowledged to function as the primary guide for strategy implementation (e.g., Burgelman, 1983a-c; Burgelman and Grove, 1996; Love et al., 2002). Burgelman (1983 c, p. 1350) argues that the "corporate concept provides a more or less shared frame of reference for the strategic actors in the organization, and provides the basis for corporate objective setting in terms of its business portfolio and resource allocation". But not only managers perceive the corporate concept as the major guiding post to which they (ideally) align their resource allocation decisions. External stakeholders such as alliance 
partners, trade unions, investors, and analysts base their assessments and forecasts on the firm's articulated corporate concept (Schmidt and Brauer, $2005,2006){ }^{2}{ }^{2}$ However, according to prior work on strategy formation (Burgelman, 1983a-c, 1991, 1994; Burgelman and Grove, 1996; Mintzberg, 1987, 1994a, b; Pettigrew, 1998), a firm's corporate concept, seems to have a certain "use-by-date" or "half-time". In this sense the corporate concept ensures an alignment of strategic actions (such as resource allocation decisions) only temporarily. This notion is mainly based on Mintzberg's (1987) early theoretical work and Burgelman's (1983a-c, 1991, 1996) studies of Intel's strategic evolution (see also Pettigrew, 1998). Both Mintzberg's (1978) and Burgelman's (1983a-c, 1994, 1996) studies purport that the "alignment between a firm's strategic intent and strategic actions is not likely to last" and that "inevitably, strategic actions will diverge from strategic intent" (Burgelman and Grove, 1996, p. 8). This proposition is indirectly supported by work on strategic sensegiving and sensemaking that found that organizations engage in continuous sensemaking processes (Bogner and Barr, 2000; Gioia and Chittipeddi, 1991). The sensegiving power of the original corporate concept may diminish over time in the light of potentially contradictory strategic sensemaking processes provoked by, for example, changes in the firm's external selection environment (Burgelman, 1994, 1996).

But while the assumption of a steady decline in strategy implementation consistency has been deeply rooted in strategy research, more recent empirical work in fact even by Mintzberg $(1993,1994 a)$ and other scholars such as D'Aveni (1995) or Love et al. (2002) implies that the explicit articulation of a corporate concept may produce inertia and thus rigidities in strategy implementation. Contrary to the assumed decline in strategy implementation consistency, we may thus be equally likely to witness a gradual increase in strategy implementation consistency over time as organizational members slowly begin to adjust to the new strategic guidelines and learn how to best implement them. In light of these contradictory findings, our first hypothesis leaves open whether strategy implementation consistency is likely to gradually increase or decline over time.

Prior research, however, suggested that whether or not a firm is able to consistently implement its strategy is not only a function of time but greatly depends on the environment in which it operates (e.g., Covin and Slevin, 1998; Venkatraman and Prescott, 1990). In extremely dynamic, so-called "high-velocity environments", the alignment between a firm's strategic concept and strategic action has been argued to be particularly difficult to achieve (Burgelman and Grove, 1996). Especially, descriptive strategy research suggests that the complex and dynamic nature of the external environment precludes deliberate control of the strategy formation process. Firms competing in high velocity environments have thus been assumed to 
show a lesser degree of strategy implementation consistency (Eisenhardt and Brown, 1999; Eisenhardt, 1989). According to Bourgeois and Eisenhardt (1988, p. 816), high-velocity environments are characterized by "rapid continuous change in demand, competitors, technology, and/or regulation, such that information is often inaccurate, unavailable, or obsolete" (see also Benner and Tushman, 2003). More than in low velocity environments, business practice in high-velocity environments has thus been characterized to involve considerable thinking ahead and adaptation en route which may lead to strategy implementation inconsistencies (Mintzberg, 1994a, p. 24). The tendency towards such adaptations en route seems also higher given that it is impossible to predict ex ante for how long a certain strategy will be valid (Eisenhardt and Brown, 1999).

Strategic flexibility - that is the ability of a firm to withdraw and dispatch resources quickly in accordance to changes and arising opportunities in the external environment - has thus been argued to be a major success factor for firms competing in high velocity environments (Hamel et al., 1999; Hitt et al., 1998, 1999; Shimizu and Hitt, 2005). To accomplish strategic flexibility, middle managers, for example, are empowered to mobilize and reconfigure resources in order to capture market opportunities faster than competition (Eisenhardt and Brown, 1999). Firms competing in high-velocity markets have thus been argued to be more likely to get into a mode of remapping businesses and resources to changing market opportunities and let strategy emerge from individual businesses - rather than attempting to rigidly adhere to the officially announced corporate concept. Such opportunityseeking behavior is likely to result in lower levels of strategy implementation consistency as the arising opportunities may well lie "outside" the scope of the announced corporate concept. In addition, as opportunities arise irregularly, these divergences are likely to occur independent of whether the corporate concept has been recently released or some time ago. In sum, the decision to adhere to or deviate from the announced corporate concept has thus been argued to be a "pervasive and potentially significant uncertainty among firms operating in competitive and dynamic environments" (Covin and Slevin, 1998, p. 208). Therefore, our second hypothesis suggests that strategy implementation consistency of firms competing in high-velocity environments is likely to be independent of time and have an upper bound due to a need for strategic flexibility.

Finally, current literature suggests that the development of strategy implementation consistency over time is also likely to be moderated by the firm's financial situation. A high degree of strategy implementation consistency has generally been perceived as an attribute of overperforming firms rather than being a constituting factor of performance itself (Covin et al., 1997, p. 23; Drazin and Van de Ven, 1985; Khandwalla, 1977; Simons, 2002b, 
p. 19; Thommen, 2003). ${ }^{3}$ Complementarily, poor strategy implementation consistency has been attributed to firms with low financial performance (Love et al., 2002). A major reason for this has been seen in the fact that overperformers presumably have a greater interest in "conserving" their level of strategy implementation consistency. As a firm's capital market performance is regarded as a proxy of stock-markets appreciation of a firm's prospects based on the existing strategy, overperformers are likely to do everything not to disappoint these positive expectations. They will try to implement their announced corporate concept accordingly. Consequently, overperforming firms are less likely to deviate from their historically-proven strategies but will try to realize an alignment between strategic decisions and the corporate concept in the future.

The increased adherence to the firm's announced corporate concept, however, does not necessarily need to be deliberate. Prior research revealed that the positive assessment of a firm's announced corporate concept by capital markets often leads to top management's unconscious "commitment to the status quo" (Hambrick et al., 1993, p. 402). The positive capital market feedback confirms top level managers in their belief in the enduring correctness of current organizational strategies.

In contrast, poorly performing firms are more likely to engage in acts of "planned flexibility". As time goes by, these firms are incentivized to deviate from their initial strategy as their future course of action appears not to be able to generate positive capital market feedback. Our third hypothesis thus suggests that the decline in strategy implementation consistency over time is less likely for overperforming firms than for underperforming firms.

\section{Methodological Design and Sampling}

In keeping with prior work (Bower, 1970; Burgelman, 1983a-c, 1991, 1994, 1996; Burgelman and Grove, 1996; Love et al., 2002; Mintzberg, 1978; Noda and Bower, 1996), strategy implementation consistency was operationalized as the alignment between the firms' strategic actions - reflected by the firms' resource allocation decisions - and the firm's articulated corporate concept.

For our analysis of the development of firms' strategy implementation consistency and its context dependency, we collected resource allocation data for twenty European multi-business firms over a period of 4-6 years. The "window" for analysis started with the announcement of a new corporate concept by the firms and ended when the firms announced an altered strategic concept. The exact temporal occurrence of a corporate concept change was confirmed either or both through the firms' management or by newspaper articles and press releases stating that the firm undertook a reformulation of its official corporate concept. 
The content of the corporate concepts was derived from either personal or second source interviews with the CEO or other member of the corporate center. Additionally, we drew on CEO speeches, road show presentations or written documents such as the letter to the shareholders/stakeholders in the firm's annual reports to derive the corporate concepts. The corporate concepts were then presented to corporate management to ensure that they truthfully and comprehensively reflected the firms' strategic intentions at that time. The review of the corporate concepts also ensured that formulated strategic intentions served as the constant strategic guidelines throughout the entire period under observation and their guiding power was not distorted by internal "on the fly" strategic adjustments that were not formally reported. We also had to ensure that each corporate concept was detailed enough to allow for a valid rating of resource allocation decisions with the concept. We were therefore only able to include firms into our sample that provided a sufficiently comprehensive and precise announced corporate strategy that could be used as a benchmark for our analysis of their strategy implementation consistency. To serve as a useful benchmark for our coding, the corporate concepts had to sufficiently reflect corporate objective setting in terms of the particular firm's business portfolio and resource allocation. This implies that not only the objectives are clearly stated but also substantiated by an outline of the planned timing, the regional focus as well as in terms of resource allocations (e.g., investments) to particular technologies, units or industries (see Table A.1 in Appendix A for sample excerpts from corporate concepts).

We concentrated on publicly listed firms as these firms face greater pressure to communicate a trustworthy blueprint of their strategic concept in contrast to private firms. Also, publicly listed firms are legally obliged to publicize relevant strategic actions ad hoc, accurately and extensively which facilitates the collection of sufficient data points and increases the reliability of the collected data. We also chose to include mostly European firms due the fact that former studies have generally relied on US firms as well as the fact that we possessed better access to these firms which allowed us to have organizational member assess the validity of our concepts. Based on this, we included the following set of companies in our empirical analysis (see Table A.2 in Appendix A).

\subsection{DATA COLLECTION}

Following, earlier empirical works by, for example, Bower (1970), Burgelman $(1983 \mathrm{a}-\mathrm{c})$ and Noda and Bower (1996), we used tangible resource allocation decisions as proxies for strategy implementation. ${ }^{4}$ In doing so, we relied on Mintzberg's (1978) definition of realized strategy as a "pattern in a stream of decisions". The individual resource allocation decision which is understood 
to reflect the organization's commitment to the strategic intent thus served as our unit of analysis.

Tangible resource allocation decisions were collected from various, public sources such as, daily editions of the international business press (Wall Street Journal Europe, Financial Times etc.), periodicals (Wirtschaftswoche, Economist, etc.), and professional news agency services (e.g., Reuters).

In total, 6238 resource allocation decisions were systematically coded and analyzed. Data collection for each case was terminated when the results remained stable, that is when additional resource allocation decisions did not seem to have further significant effect on the results. Just as in qualitative research, saturation was then assumed and data collection ceased. Following the recommendations by renowned strategy process researchers (Van de Ven and Huber, 1990; Van de Ven and Poole, 1995), we developed a database to ensure a systematic and reliable collection and analysis of the huge amount of data.

Given that we relied solely on publicly available information, our data may well be biased. Especially, how firms report resource allocation decisions could convey false impressions of the true extent of the firms' strategy implementation consistency. However, against the backdrop of the abovementioned legal obligations to publicize strategic actions in an ad hoc and true fashion, we act on the assumption that the reported resource allocation decisions provide a trustworthy picture of a firm's strategic actions. Nonetheless, we crosschecked reported decisions throughout the sample, in order to prevent us from including any "canard".

\subsubsection{Dependent variable}

3.1.1.1. Strategy implementation consistency (SIC). We used a rank-ordered indicator variable to rate the consistency of individual resource allocation decisions with the firms' individual corporate concepts on a scale from one to five. Similar to Richter's and Schmidt's (2005) classification, we used execution, compliance, diversion and contradiction as the four rank categories of SIC and added a "middle category" for those decisions that seemed to fit in neither of the four categories. Thus, we differentiated between resource allocation decisions (RAD) that precisely executed the articulated strategic intent $(\mathrm{SIC}=5)$, RAD that complied with the strategic intent $(\mathrm{SIC}=4), \mathrm{RAD}$ that could not be clearly classified $(\mathrm{SIC}=3)$, RAD that deviated from the strategic intent $(\mathrm{SIC}=2)$ and finally RAD that were outright contradictions of the articulated strategy $(\mathrm{SIC}=1)$ (see Figure 1).

In order to produce objective coding results, the RAD were assessed by two raters acting independently. The interrater reliability was around $87 \%$. If the raters disagreed on a rating of a RAD, a third assessor sought to mediate between the two. ${ }^{5}$ 


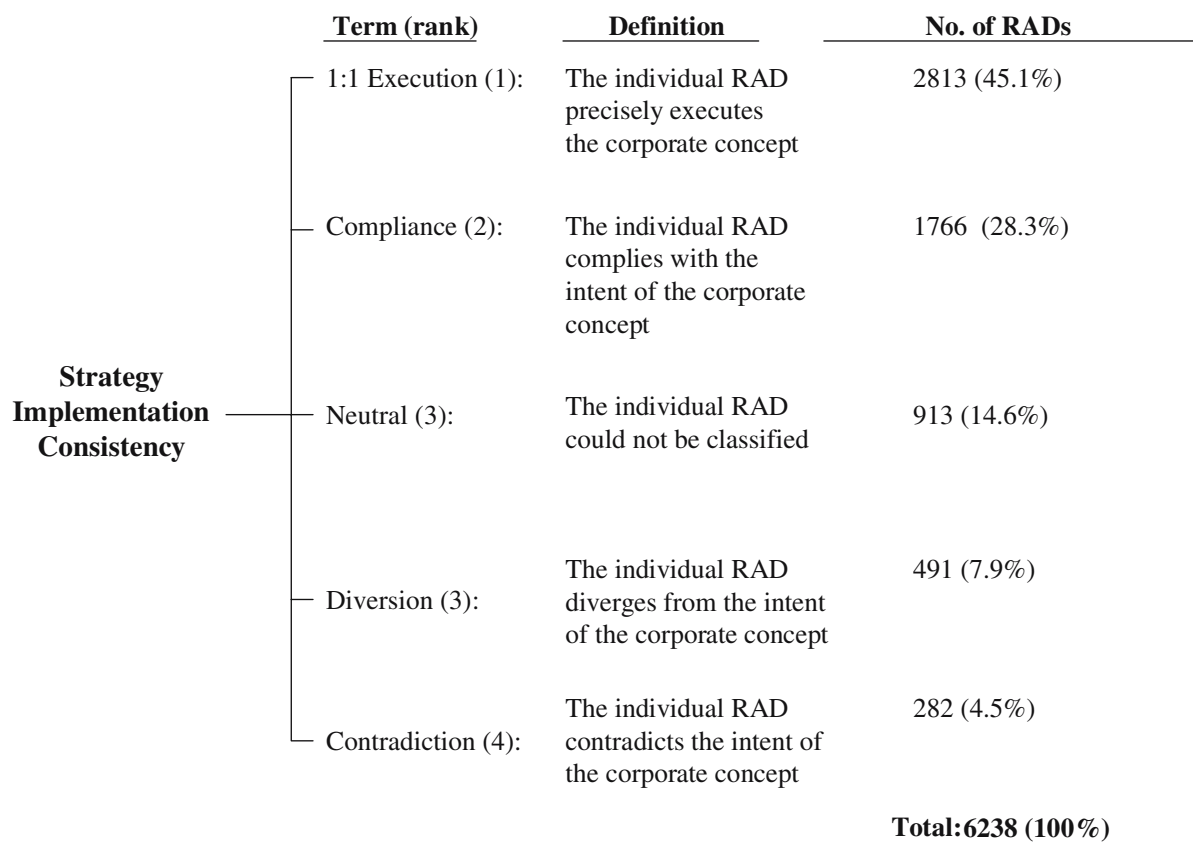

Figure 1. Coding Scheme

\subsubsection{Independent variables and controls}

3.1.2.1. Time Distance Variable (TimeDis). The time distance variable to test the potential decline in SIC over time was calculated by measuring the temporal distance (in quarters) between the official announcement of the corporate concept and the implementation of the individual RAD.

Capturing the potential moderating effect of an industry's velocity on the relationship between time and SIC, we categorized firms and thus the individual RAD into high- and low-velocity industries. We used the annual capital market raw beta-value of the industries' market returns indicating the volatility of industry market returns compared to general market returns to categorize the firms. A capital market raw beta value above 1 indicates that the industry displays greater volatility than the general market. In total, we operated with 1932 decisions taken under "high-velocity conditions" and 4306 decisions taken under "low-velocity conditions". Using market data rather than accounting data to assess an industry's volatility seems more appropriate as accounting measures such as revenues or earnings are much more prone to subjective interpretation and suffer from distortions due to the application of varying accounting standards by the firms.

In order to explore the potential moderating effect of a firm's financial position on the development of its SIC consistency over time, we determined a firm's relative performance. In accordance with Moskowitz and Grinblatt 
(1999), we compared the growth and decline rate of the indexed equity share prices with the respective sector index growth and decline rate on a monthly basis. Doing so we relied on data from Datastream and thus used the PEERICBI as the comparative index for the individual firms. If the difference between the two growth and decline rates is positive (negative) then a firm is overperforming (underperforming) its sector benchmark. In total, we thus dealt with 4430 decisions by overperformers and 1808 decisions by underperformers.

Since prior research suggested that the decision-making level may impact a firm's SIC (e.g., Bower, 1970; Burgelman, 1994, 1996) we controlled for the decision-making level (corporate, divisional, and operational) involved and whether RAD were taken jointly (in consensus) or separately by corporate and divisional managers. Two dummy variables were used for this purpose (declevel; jointdec). In case the involvement of the different managerial levels was not explicitly named in the respective data source (newspaper, journal, newsletter etc.), we relied on the financial volume (if available) of the RAD to determine the involvement and level. This seems a valid approach as most multi-business firms define, for example, hurdle investment sizes for which corporate level consent has to be given. Otherwise or when in doubt, we refrained from rating the RAD in these two control categories.

Additionally, we differentiated between financial and non-financial RAD. We did so in order to control for the effect that financial resources are potentially allocated with greater diligence than non-financial resources. This seems likely given the explicit budgeting rules and planning systems that are missing for non-financial resource allocation.

We included identifiers for the sample firms (company dummies 1-7) to control for firm specific factors such as company size.

\subsection{DATA ANALYSIS}

In order to explore the development of SIC over time as well as the potential moderating effects of the firm's environmental context and its financial position on this development, we used maximum-likelihood ordered logit estimation. The primary reason for the use of this methodology was that the dependent variable (SIC) is rank-ordered and can assume a value of one out of five categories. In such instances, ordinary least square (OLS) estimations lead to significantly distorted results (Agresti, 2002; Long, 1997). Additionally, the relationship between the dependent and the independent variables cannot be assumed as linear, so that the use of a nonlinear probability model appeared to be more appropriate than an ordered probit estimation. Maximum-likelihood ordered logit estimation allows researchers to explore how each of the various explanatory factors affects the probability that the dependent variable assumes a particular rank. The applicability of maximum-likelihood ordered 
logit estimation to the given data set was tested using the Brant-test investigating whether the distance between the different categories is equal.

We defined the odds that the consistency level variable (SIC) assumed a value less than or equal to $m$ versus greater than $m$ given the conditions specified in our model (described by the vector $\mathbf{x}$ of the independent variables):

$$
\Omega_{\leq m \mid<m}(\mathbf{x}) \equiv \frac{\operatorname{Pr}(\text { consistency } \leq m \mid \mathbf{x})}{\operatorname{Pr}(\text { concistency }<m \mid \mathbf{x})} \quad \text { for } \quad m=1, J-1 .
$$

The $\log$ of the odds is assumed to equal

$$
\ln \Omega_{\leq m \mid<m}(\mathbf{x})=\tau_{m}-\mathbf{x} \beta .
$$

The model we then estimated was

$$
\operatorname{Pr}\left(\text { concistency }=m \mid \mathbf{x}_{i}\right)=F\left(\tau_{m}-\mathbf{x} \beta\right)-F\left(\tau_{m-1}-\mathbf{x} \beta\right),
$$

where $\mathbf{x}$ was the vector of independent variables contained in our model, and $\beta$ was the vector of their respective coefficients. Furthermore, we used the Wald and lr-test in order to test whether all of the variables in a particular category or sub-category were simultaneously equal to zero. All these analyses were conducted using Stata version 9.

\section{Results and Discussion}

The results displayed in Table A.3 (see Appendix A) show that the model is characterized by a very high and significant fit level, as measured by the likelihood ratio chi-squares $\left(\chi^{2}=1283.34 * * *\right)$.

The overall predictive power of the models reaches a pseudo $R^{2}$ value of roughly 0.8 (using adjusted McFadden Pseudo $R^{2}$ ). The factors included in the model thus satisfactorily explain SIC. ${ }^{6}$

(H1:) Strategy implementation consistency is likely to gradually decline over time.

Time is found to have a significant impact on SIC $(z=-2.41)$. The sign of the coefficient for the time distance (TimeDis) measure is negative (coef. $=-0.0113$ ). Other than in ordinary regression analysis, the coefficients in ologit models are less straightforward to interpret. Rather than depicting the effect of the independent variables on the dependent variable (in percent), the coefficients only display the logarithmic odds ratios. The odds ratio is the number by which we would multiply the odds of a RAD of being in a certain consistency category for each one unit increase in the independent variable, holding all other factors constant. Thus, the signs of the coefficient rather than the coefficient itself is of interest. The negative sign implies that RAD 
that are taken early on - relative to when the announcement of the new corporate concept occurred - are likely to be more consistent than those decisions that are taken late in the strategy implementation process.

The coefficients of the company dummies (companies 1-7) show both positive and negative signs. Of greater interest, however, is that when we used the Wald and lr-test in order to test whether the firms were simultaneously equal to zero, we found that the companies are clearly distinct from each other so that the company characteristics can be argued to influence $\operatorname{SIC}\left(\chi^{2}=-591.73^{* * *}\right)$. The fairly large standard errors of the company dummies indicate that in all of the firms we find a mix of decisions that range from being highly consistent to being outright contradictory to the announced corporate concept.

The $z$-values for the two variables meant to control for the decision-making level and the type of decision-making (joint versus individual) turn out to be positive (coef. $=0.6$; coef. $=0.48)$ and highly significant $(z$-value $=10.41 ; z$ value $=5.86)$. The paper thus unravels that strategic implementation inconsistencies may not originate mostly from autonomous behavior by lower level managers. Instead, it seems that decisions by operational managers are in fact highly consistent with the firms' corporate concept. This finding may be interpreted in the way that we are in fact looking at top-down initiated "controlled emergence" and not so much at autonomous behavior that is responsible for the strategic inconsistencies. Counter to prior evidence, our findings suggest that SIC may be positively related with the extent to which operational levels are granted discretion in implementing strategy.

In addition, financial resource allocation decisions are found to be taken with much greater diligence to the announced corporate concept than nonfinancial RAD as indicated by both the positive coefficient (0.44) and the significant $z$-value (7.63).

(H2:) Strategy implementation consistency of firms competing in highvelocity environments is likely to be independent of time.

The sign of the coefficient for TimeDis continues to remain negative (coef. $=-0.011)$ but is insignificant $(z$-value $=-1.22)$. In high-velocity contexts, the likelihood for a RAD to fall into either of the five different categories of SIC 1-5 thus seems independent of when the RAD is actually taken. This finding revokes the common notion that strategy implementation declines gradually and the complementary notion that the sooner after the announcement of a new corporate concept a resource allocation is taken, the greater the likelihood that it is consistent with that concept (Pettigrew, 1998; Pettigrew and Whipp, 1991). The (null) hypothesis that SIC of firms competing in high-velocity environments is independent of time is thus supported. For decisions taken in a low-velocity environment, in contrast, we find that SIC gradually declines over time $(z$-value $=-8.11)$ 
(H3:) The decline in strategy implementation consistency over time is less likely for overperforming firms than for underperforming firms.

The TimeDis has a negative coefficient (coef. $=-0.052$ ) and is highly significant $(z$-value $=-8.39)$. Contrary to our expectations, overperforming firms surprisingly do not seem to be able or willing to maintain a closer alignment of strategic actions with their announced corporate concept over time. Based on these results, hypothesis 3 can be rejected. In line with our expectations, SIC for underperforming firms is found to decline (coef. $=-0.047 ; z$-value $=-4.59$ ).

\section{Discussion of Results}

The paper set out to empirically investigate the common presumption that divergences between strategy and action - in form of resource allocation - unavoidably emerge over time (Burgelman and Grove, 1996, p. 24). The study unravels that firms usually do not persist with predetermined and intended corporate strategies over longer periods of time. Instead, they are found to extensively diverge from their corporate concept - either in a planned or unplanned way. Our study thereby empirically confirms prior qualitative case study research proposing a decline of SIC over time (e.g., Burgelman and Grove, 1996; Pettigrew, 1998; Richter and Schmidt, 2005).

Our results confirm that firms in high-velocity environments may truly engage in continuous withdrawal and dispatching processes in accordance to changes in the firm's environments (Eisenhardt and Brown, 1999; Shimizu and Hitt, 2005). Firms competing in high-velocity environments thus seem to embrace a mode of strategizing that is distinctly different from strategizing in low-velocity environments. Since the environment is in flux requiring constant external realignment, firms in high-velocity environments seem indeed concerned with adaptive generalization (Dunn, 1971). The process of adaptive generalization incurs that the alignment to a firm's corporate concept is consciously or unconsciously disturbed for the sake of a newer or higher fit to emerging opportunities (Chakravarthy, 1982; Dunn, 1971).

Our empirical results may on the one hand indicate that a high level of uncertainty and ambiguity (as you find in high-velocity environments) leads firms to prematurely react to perceived changes in their external environment. On the other hand, in high-velocity environments (especially software), firms may deliberately float "trial balloons" of upcoming initiatives (especially new product launches) to gauge a first market reaction. In case that markets react positively they carry on, otherwise they change the strategic path which results in SIC. 
Furthermore, prior research has found that firms competing in highvelocity environments are often more entrepreneurial than those competing in stable environments which may additionally spur SIC (Zahra, 1991, 1993). In this respect, our decision control variables, however, offer some interesting insights that entrepreneurial behavior may not necessarily emerge from the bottom of the organization. Divisional and operational managers' RAD have been found to be mostly consistent with the firms' corporate concept.

Moreover, we find that overperforming firms are unable or unwilling to conserve their SIC. However, similar to our findings on the impact of highvelocity conditions on the development of SIC, our results offer no clear indication for why overperforming firms digress from their corporate concept even though they should be interested in continuing their strategy which has been approved of by capital markets in the past. One reason for that course of action might be that firm's in a comfortable financial position do not see themselves to the same degree subject to close capital market scrutiny as low-performing firms would do. Moreover, overperforming firms with greater financial resource slack generally tend to engage in higher levels of exploration activities. Exploratory activities - in contrast to exploitative activities that have been found to be the dominant modus operandi for low-performing firms - by nature are causing divergences from the beaten strategic path. These may be rather outflows of planned rather than unplanned emergence. In the case of planned emergence, our results suggest that successful firms do not merely seem to attempt to please financial markets by engaging exclusively in exploitation activities. Instead, these firms seem to allow inconsistent bottom-up initiatives to partly prevail over their original corporate concept. Our findings would thus confirm earlier presumptions in strategy research (e.g., Burgelman, 1991) that firms who are successful over longer time periods maintain both top-driven strategy implementation and bottom-up driven internal experimentation processes. Moreover, overperforming firms displaying higher strategy implementation inconsistencies might be quicker in responding to unforeseen changes in the external environment. At least they seem to be better in identifying arising opportunities and to patch business units accordingly (Eisenhardt and Brown, 1999). Higher strategic inconsistencies in these firms may thus simply be an indicator for their superior corporate learning abilities. Overall, the results may thus be seen as an indication for the fact that the financial position of a firm itself is a contingency that partly determines the firm's strategy implementation process as the financial position may impact firms' responsiveness, level of opportunity seeking and exploratory behavior (e.g., Chakravarthy and Lorange, 1991; Hart and Banbury, 1994). 


\section{Limitations and Directions for Future Research}

We recognize that our results can only be an intermediate, though significant, step towards a better understanding of SIC. Our findings should be viewed in the light of the following shortcomings of our approach, which may be amended by future research.

First, our methodological approach exclusively focuses on observable RAD and thus does not comprehensively capture strategy implementation processes. Though our decision control variables offer some insights into whether we are dealing with planned or unplanned emergence, the use of secondary information only does not allow for a clear separation of "erratic" and "flexible" corporate moves, i.e. we do not capture in our coding whether firms allocate resources contrary to their corporate concept on purpose (e.g., applying a hedging strategy) or by accident. Further research should complement the applied outside-in view with an inside-out perspective. Greater reliance on primary data and ideally on participatory observations may help to tell planned flexibility apart from unplanned flexibility and therefore allow the distinction between "erratic" and "flexible" ways of strategy implementation.

Second, we are aware that the announced corporate concept - despite our triangulation with multiple data sources and the review by corporate managers - does not reveal intended strategies to their full extent, given that firms might not communicate confidential elements to the public due to competitive concerns. However, recent requests (e.g., code of conducts, stock exchange rules, regulatory requirements) for greater transparency (Theisen, 2003) allow us to assume that the difference between a firm's announced and unofficial (intended but not communicated) corporate concept is likely to be almost negligible. Publicly listed firms can barely afford not to announce their real intentions, unless they want to incur reputational risks or evaluation discounts for a lack of transparency (Jörg et al., 2004). For instance, if financial markets or alliance partners infer that the focal firm is not presenting its true strategic goals, they tend to mistrust the firm's actions and become less likely to enact cooperative behavior (Butler, 1995).

Third, the statistical results might not be surprising due to the fact that our sample only includes multinational corporations (MNCs). Inconsistency in strategy implementation is more likely in MNCs because of the higher level of uncertainty they face in their competitive environment. In addition, more than small firms, MNCs tend to hedge different business risks. So they vary the proportion of resources that is allocated to implement the announced corporate concept. For instance, managers start allocating some resources into several new business lines (which is part of a new corporate concept) and see what happens in order to subsequently "pull the plug" or "dive in" over the course of time. Further analyses investigating SIC in small to medium sized firms may thus be of interest. 


\section{Theoretical and Practical Implications}

The current study is among the very few studies that set out to empirically investigate the development of strategy formation. Specifically, our quantitative study contributes to extant literature by probing the applicability of generally held presumptions on the development of SIC over time. It is therefore directly responsive to claims for more process related work on strategy formation and its underlying assumptions (Lovas and Ghoshal, 2000; Mintzberg and Waters, 1985).

Furthermore, our study complements and extends prior mostly conceptual or qualitative strategy process studies (Bower, 1970; Burgelman, 1983a, b; Mintzberg and McHugh, 1985) by unravelling whether firms persist with or diverge from predetermined and intended corporate strategies - either in a planned or unplanned way.

Finally, our paper aims to shed light on the central dimensions of strategy process research outlined by Pettigrew (1992) - the consideration of time, contexts and the link of process factors to performance. We directly address the temporal and context dimension by analyzing the development of SIC over time as well as the moderating effects of selected internal and external context factors. In addition, we indirectly link our process analysis to firm performance by considering the potential moderating effect of a firm's financial position on the development of SIC over time.

\subsection{PRACTICAL IMPLICATIONS}

Corporate level managers are charged with the daunting task of securing the alignment of strategic actions with the announced corporate concept. Decentralized decision-making, regional dispersion, the pressure to satisfy multiple, often contradictory, constituents inside and outside the organization as well as the close scrutiny of financial markets further complicate this task for corporate level managers. Our analysis of SIC reveals that managers need to steer their firms similar to airplanes. Despite their "navigation systems" (e.g., controlling, incentive systems) firms - like airplanes - never seem to stay completely on course for longer periods of time. Instead, firms implement their strategy within a certain bandwidth of consistency at different points in time. This analogy seems to be particularly true for highvelocity environments where firms display an incoherent temporal pattern of SIC. Firms competing in high-velocity environments are found to "sway off course" and then "pull back on course" while the likelihoods for swaying off and pulling back seem influenced by arising opportunities. Firms competing in high-velocity environments are thus better off to develop strategic flexibility rather than relying on long-term strategic planning cycles (Hamel et al., 1999; Hitt et al., 1999). This means that in such contexts, managers need to 
learn to withdraw and dispatch resources quickly in accordance to changes and arising opportunities in the external environment. In this sense we agree with Mintzberg and Waters (1985) who noted that "strategy formation walks on two feet, one deliberate, and the other emergent (...) managing requires a light deft touch - to direct in order to realize intentions while at the same time responding to an unfolding pattern of decisions" (1985, p. 271).

\section{Acknowledgements}

We would like to thank the editor and the two reviewers for offering invaluable comments on earlier versions of the paper. Further, we would like to thank our research partners Prof. Dr. Ansgar Richter, Prof. Dr. Jean-Paul Thommen, and Prof. Dr. Martin Welge. In addition, we acknowledge Guenter Mueller-Stewens, Steven Floyd and Raghu Garud for their highly regarded and valuable advice, in addition to Jeffrey Covin and Tony Simons for their comments on our consistency research in general. Furthermore, we are grateful to the group of doctoral students from the International Corporate Strategy (ICS) research project for their contributions to data collection, productive conversations and comments on our research. Finally, we wish to express our thanks to the Swiss National Fund (SNF) for financing parts of our research.

\section{Notes}

${ }^{1}$ Mintzberg (1978) talks about the deliberateness of strategy formation in this regard. A high degree of deliberateness is equivalent to a low share of emergent elements within the realized strategy.

2 A corporate concepts is thus an extended and more detailed version of a firm's corporate strategy that traditionally only provides answers to the question of what business the firm is in.

${ }^{3}$ In this respect, overperformance means financial performance that is superior to a firm's peers in the same industry.

${ }^{4}$ The exclusive focus on tangible resources is a widely used approach in strategy research due to the methodological problems associated with monitoring and measuring intangible resources (Barney et al., 2001).

5 In accordance with Van de Ven and Poole (1995), we refrained from weighing RAD by transaction volume or potential strategic importance to keep our data unbiased. Mintzberg $(1994 \mathrm{a}, \mathrm{b})$ also noted that it is often very difficult to judge whether a decision is of strategic importance for a firm or not: "What seemed tactical yesterday might prove strategic tomorrow" (1994a, b p. 27).

${ }^{6}$ The pseudo $\mathrm{R}^{2}$ is defined as $1-\mathrm{L} 1 / \mathrm{L} 0$ where $\mathrm{L} 1$ is the log likelihood of the model concerned and L0 is the log likelihood of the "constant-only" model. Such, the pseudo $\mathrm{R}^{2}$ lacks the straightforward explained-variance interpretation of true $\mathrm{R}^{2}$ in ordinary least squares. 


\section{Appendix A}

Table A.1. Sample excerpts from corporate concepts

- "The approximately $€ 2$ billion extraordinary charge for restructuring measures posted in the fiscal 1998 balance sheet will largely be used to remedy problems at SemiconU, to integrate USCo operations, and for measures in the new information and communications business segment" (Siemens Corporate Concept 1998).

- "Be present in $50 \%$ of highly attractive disease areas and achieve a tier-1 position in half of them. Focus on diseases with unmet (or unsatisfactorily met) medical needs and develop (incremental) innovations for them" (Novartis Corporate Concept 2003).

- "Increase investments in emerging markets especially in Asia. Increase the turnover in Asia from today 13 to $20 \%$ and at the same time increase the local production from 40 to $70 \%$ until 2010 . Be amongst the top three suppliers in all business units. These units are: Chemicals, Plastics and Fibers, Coatings, Plants protection and Nutrition, Oil and Gas (BASF Corporate Concept 2000).

Table A.2. Sample firms

Accenture
Allianz
BASF
Beiersdorf
Carrefour
Clariant
Credit Suisse Group
Daimler Crysler
Deutsche Bank
Deutsche Telekom
EON
Henkel
LVHM
Metro
Nestle
Novartis
Preussag/TUI
RWE
Siemens
Unilever


THE MODERATING EFFECTS OF INDUSTRY VELOCITY AND FIRM PERFORMANCE 223

Table A.3. Ordered logistic regression

\begin{tabular}{|c|c|c|c|}
\hline \multicolumn{2}{|l|}{ Log likelihood $=-7517.76$} & \multicolumn{2}{|c|}{ Pseudo $R^{2}=0.0787$} \\
\hline Strategy Implementation Consistency & Coefficient & Std. Err. & $z$-Value \\
\hline TimeDis(Q) & $-0.015^{* *}$ & 0.0062 & -2.41 \\
\hline Decision-Level & $0.604 * * *$ & 0.058 & 10.41 \\
\hline Joint-Dec & $0.48 * * *$ & 0.082 & 5.86 \\
\hline ResType & $0.437 * * *$ & 0.0573 & 7.63 \\
\hline Company 1 & $-1.049^{*}$ & 0.617 & -1.70 \\
\hline Company2 & $-1.65 * *$ & 0.639 & -2.58 \\
\hline Company3 & $-1.75 * *$ & 0.618 & -2.83 \\
\hline Company4 & $-1.155^{*}$ & 0.629 & -1.84 \\
\hline Company5 & -0.26 & 0.635 & -0.41 \\
\hline Company6 & $-0.933^{*}$ & 0.62 & -1.50 \\
\hline Company7 & $-1.544 *$ & 0.666 & -2.32 \\
\hline Company8 & -0.527 & 0.616 & -0.86 \\
\hline Company9 & $-1.409^{*}$ & 0.626 & -2.25 \\
\hline Company 10 & $-2.165^{* * *}$ & 0.615 & -3.52 \\
\hline Company11 & $-1.01^{*}$ & 0.616 & -1.64 \\
\hline Company 12 & $-1.4^{*}$ & 0.62 & -2.25 \\
\hline Company13 & $-2.335 * * *$ & 0.623 & -3.75 \\
\hline Company14 & $-1.756^{* *}$ & 0.6113 & -2.87 \\
\hline Company 15 & $-1.562 * *$ & 0.632 & -2.47 \\
\hline Company 16 & -0.54 & 0.614 & -0.88 \\
\hline Company17 & 0.167 & 0.627 & 0.27 \\
\hline Company 18 & -0.291 & 0.615 & -0.47 \\
\hline Company 19 & $-1.622 * *$ & 0.616 & -2.63 \\
\hline Company20 & -0.219 & 0.623 & -0.35 \\
\hline \multicolumn{4}{|l|}{$\dagger^{\dagger} p<0.10$} \\
\hline \multicolumn{4}{|l|}{$* p<0.05$} \\
\hline \multicolumn{4}{|l|}{$* * p<0.01$} \\
\hline \multicolumn{4}{|l|}{$* * * p<0.001$} \\
\hline \multicolumn{4}{|l|}{ Ordered logistic regression } \\
\hline \multicolumn{4}{|l|}{ Number of observations $=6238$} \\
\hline \multicolumn{4}{|l|}{$\operatorname{LR} \chi^{2}(15)=1283.88^{* * *}$} \\
\hline$P>\chi^{2}=0.0000$ & & & \\
\hline
\end{tabular}

\section{References}

Agresti, A.: 2002, Categorical Data Analysis (Hoboken: John Wiley and Sons).

Barney, J., M. Wright and D.J. Ketchen: 2001, "The Resource-based View of the Firm: Ten Years After 1991", Journal of Management 27(6): 625-641.

Benner, M.J. and M.L. Tushman: 2003, "Exploitation, Exploration and Process Management: The Productivity Dilemma Revisited”, Academy of Management Review 28(2): 238-256. 
Bogner, W. and P. Barr: 2000, "Making Sense in Hypercompetitive Environments: A Cognitive Explanation of the Persistence of High-Velocity Competition", Organization Science 11(2): 212-226.

Bourgeois, L.J. and K.M. Eisenhardt: 1988, "Strategic Decision Processes in High Velocity Environments: Four cases in the Microcomputer Industry", Management Science 34(7): $816-835$

Bower, J.L.: 1970, Managing the Resource Allocation Process (Boston, MA: Harvard Business School Press).

Burgelman, R.A.: 1983a, "A Model of the Interaction of Strategic Behavior, Corporate Context, and the Context of Strategy", Academy of Management Review 8(1): 61-70.

Burgelman, R.A.: 1983b, "A Process Model of Internal Corporate Venturing in the Diversified Major Firm", Administrative Science Quarterly 28(2): 223-244.

Burgelman, R.A.: 1983c, "Corporate Entrepreneurship and Strategic Management: Insights from a Process Study", Management Science 19: 1349-1364.

Burgelman, R.A.: 1991, "Intraorganizational Ecology of Strategy Making and Organizational Adaptation: Theory and Field Research", Organization Science 2: 239-262.

Burgelman, R.A.: 1994, "Fading Memories: A process Theory of Strategic Business Exit in Dynamic Environments”, Administrative Science Quarterly 39(1): 24-56.

Burgelman, R.A.: 1996, “A Process Model of Strategic Business Exit in Dynamic Environments", Strategic Management Journal 17: 193-214.

Burgelman, R.A. and A.S. Grove: 1996, "Strategic Dissonance", California Management Review 38(2): 8-28.

Butler, J.K.: 1995, "Behavior, Trust and Goal Achievement in a Win-win negotiating Role Play", Group \& Organization Management 20(4): 486-501.

Chakravarthy, B.S.: 1982, "Adaption: A Promising Metaphor for Strategic Management", Academy of Management Review 7(1): 35-44.

Chakravarthy, B.S. and R.E. White: 2001, "Strategy Process: Forming, Implementing and Changing strategies", in A. Pettigrew, H. Thomas and R. Whittington (eds.), Handbook of Strategy and Management (London: Sage Publications), pp. 182-205.

Covin, J., D. Slevin and R. Schultz: 1997, “Top Management Decision Sharing and Adherence to Plans", Journal of Business Research 40: 21-36.

Covin, J. and D. Slevin: 1998, "Adherence to Plans, Risk Taking, and Environment as Predictors of Firm Growth", Journal of High Technology Management Research 9(2): 207237.

D’Aveni, R.: 1995, “Coping with Hypercompetition”, Academy of Management Executive 9(3): 45-60.

Drazin, R. and A.H. Van de Ven: 1985, "An Examination of Alternative Forms of Fit in Contingency Theory", Administrative Science Quarterly 30: 514-539.

Dunn, E.S.: 1971, Economic and Social Development: A Process of Social Learning (Baltimore: John Hopkins University Press).

Eisenhardt, K.: 1989, "Building Theories from Case Study Research", Academy of Management Review 14(4): 532-550.

Eisenhardt, K.M. and S.L. Brown: 1999, "Patching - Restitching Business Portfolios in Dynamic Markets", Harvard Business Review, May-June: 72-82.

Gioia, D.A. and K. Chittipeddi: 1991, "Sensemaking and Sensegiving in Strategic Change Initiation", Strategic Management Journal 12(3): 433-448.

Hambrick, D., M. Geletkanycz and J. Fredrickson: 1993, “Top Management Commitment to the Status Quo: Some Tests of its Determinants", Strategic Management Journal 14: 401-418.

Hamel, G., C.K Prahalad, T. Howard and D. O’Neal (eds): 1999, Strategic Flexibility: Managing in a Turbulent Environment (New York: John Wiley and Sons). 
Hart, S. and C. Banbury: 1994, "How Strategy-Making Processes can make a Difference", Strategic Management Journal 15: 251-269.

Hitt, M.A., B.W. Keats and S.M. DeMarie: 1998, "Navigating in the New Competitive Landscape: Building Strategic Flexibility and Competitive Advantage in the 21 st Century", Academy of Management Executive 12(4): 22-42.

M.A. Hitt, J.E. Ricart, I. Costa and R.D. Nixon (eds): 1999, New Managerial Mindsets: Organizational Transformation and Strategy Implementation (New York: John Wiley and Sons).

Jörg, P., C. Loderer and L. Roth: 2004, "Shareholder Value Maximization: What Managers Say and What They Do", Die Betriebswirtschaft 64(3): 357-377.

Khandwalla, P.N.: 1977, The Structuring of Organizations. Design of Organizations (New York).

Long, J.S.: 1997, Regression Models for Categorical and Limited Dependent Variables (Thousand Oaks: Sage Publications).

Lovas, B. and S. Ghoshal: 2000, "Strategy as Guided Evolution", Strategic Management Journal 21: 875-896.

Love, L., R. Priem and G. Lumpkin: 2002, "Explicitly Articulated Strategy and Firm Performance Under Alternative Levels of Centralization", Journal of Managfement 28(5): 611-627.

McGregor, D.: 1967, The professional manager, (New York: McGraw-Hill).

Mintzberg, H.: 1977, "Strategy Formulation as an Historical Process", International Studies of Management and Organization 7(2): 28-42.

Mintzberg, H.: 1978, "Patterns in Strategy Formation", Management Science 24(9): 934-948.

Mintzberg, H.: 1987, "Strategy Concept I: Five P's for Strategy", California Management Review, 30(1): 11-24.

Mintzberg, H.: 1993, Structure in Five Designing Effective Organizations (Englewood Cliffs: Prentice Hall).

Mintzberg, H. and J.A. Waters: 1982, "Tracking Strategy in an Entrepreneurial Firm", Academy of Management Journal, 466-499.

Mintzberg, H. and J.A. Waters: 1984, "Researching the Formation of Strategies: The History of Canadian Lady", in R. Lamb (ed.), Competitive Strategic Management (Englewood Cliffs: Prentice-Hall).

Mintzberg, H. and J.A. Waters: 1985, "Of strategies, deliberate and emergent", Strategic Management Journal 6: 257-272.

Mintzberg, H. and K. McHugh: 1985, "Strategy formulation in an adhocracy", Administrative Science Quarterly 30: 257-272.

Mintzberg, H.: 1990a, "Strategy formation: Schools of thought", in J.W. Fredrickson (ed.), Perspectives on Strategic Management (New York: Harper Business), pp. 105-236.

Mintzberg, H.: 1990b, “The Design School: Reconsidering the Basic Premises of Strategic Management", Strategic Management Journal 11: 171-195.

Mintzberg, H.: 1994a, "The Fall and Rise of Strategic Planning", Harvard Business Review 72(1): $107-115$.

Mintzberg, H.: 1994b, The Rise and Fall of Strategic Planning (New York: Prentice Hall).

Moskowitz, T.J. and M. Grinblatt: 1999, “Do Industries Explain Momentum?”, The Journal of Finance. 54(4): 1249-1290.

Noda, T. and J.L. Bower: 1996, "Strategy Making as Iterated Processes of Resource Allocation", Strategic Management Journal 17(Special Issue Summer): 159-192.

Pettigrew, A.: 1992, "The Character and Significance of Strategy Process Research", Strategic Management Journal 13: 5-16. 
Pettigrew, A.M. and R. Whipp: 1991, Managing Change for Competitive Success, (Basil: Blackwell).

Pettigrew, A.M.:1998, "Success and Failure in Corporate Transformation Initiatives", in R.D. Galliers and W.R. Baets (eds.), Information Technology and Organizational Transformation, (New York: John Wiley) 271-289.

Richter, A. and S. Schmidt,: 2005, "How does Strategy Process Influence Strategy Content? Antecedents of Consistency between Resource Allocation Decisions and Corporate Strategy", Schmalenbach Business Review 57(4): 332-350.

Schmidt, S.L. and M. Brauer: 2005, Corporate Governance: Möglichkeiten des Aufsichtsrats zur sachgerechten Kontrolle von Managerverhalten und Firmenpolitik", The German Journal of Industrial Relations 12(3): 306-322.

Schmidt, S.L. and M. Brauer: 2006, "Strategic Governance: How to Assess Board Effectiveness in Guiding Strategy Execution", Corporate Governance: An International Review 14(1): 12-21.

Shimizu, K. and M. Hitt: 2005, "Strategic Flexibility: Organizational Preparedness to Reverse Ineffective Strategic Decisions", Academy of Management Executive 18(4): 44-59.

Simons, T.L.: 1999, "Behavioral Integrity as a Critical Ingredient for Transformational Leadership", Journal of Organizational Change Management 12(2): 89-110.

Simons, T.: 2002a, "Behavioral Integrity: The Perceived Alignment Between Managers' Words and Deeds as a Research Focus", Organization Science 3(1): 18-35.

Simons, T.: 2002b, "The High Cost of Lost Trust", Harvard Business Review 80: 18-20.

Simons, T. and Q. Roberson: 2003, "Why Managers Should Care about Fairness: The Effects of Aggregate Justice Perceptions on Organizational Outcomes", Journal of Applied Psychology 88(3): 432-43.

Theisen, M.: 2003, Herausforderung Corporate Governance", Die Betriebswirtschaft 63(4): $441-464$.

Thommen, J-P.: 2003, "Glaubwürdigkeit und Corporate Governance", Zürich 2003.

Van de Ven, A.H. and G.P. Huber: 1990, "Longitudinal Field Research Methods for Studying Processes of Organizational Change", Organization Science 1(3): 213-219.

Van de Ven, A.H. and M.S. Poole: 1995, "Methods for Studying Innovation Development in the Minnesota Innovation Research Program", in G.P. Huber and A.H. VenVan de (eds.), Longitudinal Field Research Methods. Studying Processes of Organizational Change (Thousand Oaks: Sage Publications), pp. 155-185.

Venkatraman, N. and J. Prescott: 1990, "Environment-strategy coalignment: An empirical test of its performance implications", Strategic Management Journal 11(1): 1-23.

Weick, K.E.: 1995, Sensemaking in Organizations (Thousand Oaks: Sage Publications).

Zahra, S.: 1991, "Predictors and Financial Outcomes of Entrepreneurship: An Exploratory Study", Journal of Business Venturing 6: 259-285.

Zahra, S.: 1993, "Environment, Corporate Entrepreneurship and Financial Performance: A Taxonomic Approach", Journal of Business Venturing 8: 319-340. 